\title{
Analysis the Residual Stress of cutting tool insert in turning of Mild Steel -A Review
}

\author{
C. Ramesh kannan ${ }^{1}$, K. Vignesh ${ }^{2}$ and P. Padmanabhan ${ }^{3}$ \\ ${ }^{1}$ Faculty, Department of Mechanical, Anna University Regional \\ Campus, Madurai \\ ${ }^{2 *}$ P.G Scholar, Department of Mechanical, Anna University Regional \\ Campus, Madurai \\ ${ }^{3}$ Principal, V. V. Engineering College, Tisaiyanvillai vigneshsrivi93@gmail.com
}

\begin{abstract}
Residual stress is an important factor in machining process an attempt has been made to analyze the residual stress in turning of AISI4340 steel. The residual stresses that can be found in a cutting tool insert are mainly generated at the final step of the machining process. Feed, speed, depth of cut are the input parameter. The residual and the tool wear are the output responses. Cryogenic treatment will improve the performance and made significant of wear resistance, better residual stress and product quality of cutting tool. This is the study of review the literature from performance of cryogenically treated cutting tool insert in varying nose radius and the soaking period. The level of the generated residual stress depends on the machine materials and on the process parameters used. The overall goal of the present paper is to identify an analytical relationship between residual stress and turning process parameters accounting also for the material being machined.
\end{abstract}

Keywords: Cryogenic treatment, turning, residual stress, wear

\section{Introduction}

Manufacturing industries are need for lower cost solutions in order to maintain their competitiveness on manufactured goods. Product quality has been found as the most important part of the manufacturing industry and it continues to improve, depend up on the competition and buyer strategies. The recent trend is toward higher quality, lower cost and smaller batch sizes, it is necessary to find out new technology that can help us to improve the business field. Many studies reported that some mechanical and physical properties of tool materials showed that tool life of treated and tempered inserts substantially improved (up to $126 \%$ ). The mechanism of residual stresses generation is still not completely recognized. The hard steel turning introduces compressive residual stresses in surface and in the subsurface of the work piece increasing with this its fatigue resistance [1]. Turning is the removal of metal from the work piece and obtained requires kind of shape and size. Turning of ferrous and nonferrous material like steel, fiber, plastic and metal matrix composition and differ from the various applications. The turning parameters are depending up on the material selection and the machining conditions. The Computer Numerical Control (CNC) lathe operation is the most convenient way to compare the conventional lathe operation. These are classified as three axle and five axle lathes [2]. Few researchers analyze the effect of cryogenic treatment of different materials and various materials conditions. The aim of the review is to analyze the effect of process parameter namely feed, speed, depth of cut during turning of AISI 4340 steel using cryogenic treatment. The first one is deals with cryogenically treatment and second one is deals with experimental details and the last one is analyze the residual stress. 


\section{Review of Literature Survey}

In turning operation there are three major responses are involved they are cutting temperature zone, tool wear and surface roughness. The input parameters are cutting Speed, feed rate and depth of cut. Higher cutting speed and lower feed rate produce better surface finish and the material removal rate is high when increasing the depth of cut. The surface roughness is proportional to the material hardness, feed rate and inversely proportional to the cutting speed. For high finish turnings, high cutting speed is recommended. The machining of material is to exhibit some stresses, especially at its free ends of the surface. These stresses that remain in the material after the loading is removed are called residual stresses. The change of shape of the tool from its original shape, during cutting, resulting from the gradual loss of tool material is termed as tool wear. They are in metal-to-metal contact between the chip and work piece, under conditions of very high stress at high temperature. Wear occurs during the cutting action, and the ultimate result is the failure of the cutting tool [3].

\subsection{Effect of Process Parameter in Turning}

Sreeramareddy et al., showed the Machinability of C45 steel with deep cryogenic treated tungsten carbide cutting tool inserts. The cutting parameters are depth of cut of 1 $\mathrm{mm}$, feed rate $0.22 \mathrm{~mm} / \mathrm{rev}$ and cutting speeds $200,250,300$ and $350 \mathrm{~m} / \mathrm{min}$, under dry conditions [4]. The improvement in flank wear resistance was $21.2 \%$ and tool life was $11.1 \%$ of the low temperature treated inserts were better when compared to untreated inserts. The main cutting forces for the low temperature treated inserts were lesser when compared to untreated inserts. Also, the surface finish was better with treated inserts when compared with untreated inserts at all cutting speed. He concluded that result as decrease in main cutting force of $2.0 \%$ and improvement in surface roughness of the work piece of $8.42 \%$. Tamizharasan et al., [5] analyzed the tool wear and surface finish in hard turning. In the experimental investigation the cutting speed had a considerable effect on tool wear. When the cutting speed was reduced by $50 \%$ and feed rate was increased by $50 \%$, the material removal rate was same and tool life was slightly increased. The tool wear was affected by the cutting speed. The feed affected it to some extent. And the depth of cut had only negligible effects on tool wear. The grades of cutting tool affected tool wear to a considerable extent, relative to the effects of material of work-piece on tool wear. Jitendra Varma et al., [6] conducted the Turning parameter optimization for surface roughness of ASTM a242 type-1 alloys steel. The cutting parameters such as cutting speed, feed rate and depth of cut which were varied through three levels. And the results are cutting speed is the only significant factor which contributed $57.47 \%$ to the surface roughness. The second factor which contributed to surface roughness was the feed rate having $23.46 \%$ and the third factor which contributed to surface roughness was the depth of cut having $16.27 \%$. It is recommended from the above results that cutting speed of 18.30 to $15.78 \mathrm{~m} / \mathrm{min}$ can be used to get lowest surface roughness. Suhail et al., [7] performed an optimization of cutting parameters based on surface roughness and Assistance of work piece surface temperature in turning process. The settings of cutting speed include 950, 1150 and $1400 \mathrm{rpm}$; the feed rate include $0.05,0.1,0.15 \mathrm{~mm} / \mathrm{rev}$; the depth of cut is set at $0.5,1.0$ and $1.5 \mathrm{~mm}$. It was found according to the rank value for each control factor that, the feed rate had the strongest influence on surface roughness followed by cutting speed and depth of cut. The optimal cutting parameters for surface roughness are the feed rate at level 1, the cutting speed at level 3, and depth of cut at level 3. Nilrudra Mandal et al., [8] investigated on the optimization of machining parameters in turning AISI 4340 steel. The Zirconia toughened alumina inserts were selected to machine the selected work piece. It was concluded that at constant cutting speed and feed rate, when depth of cut increased, the flank wear and cutting force decreased and then significantly increased but increment of surface roughness value was less at higher cutting 
speed. For the constant cutting speed and depth of cut when feed rate increased the flank wear and cutting force increased but surface roughness significantly decreased. Based on the literature review of the most relevant process parameters are feed, speed and depth of cut. These input parameters are to be influenced by the turning operation.

\subsection{Work Material and Tool Material}

Prachee Srivastava and Ashish Arya [9] showed with Improvement in surface quality with different Material as Solid Lubricant in Turning on AISI 4340 Steel. The work material used in this paper is AISI 4340 Steel and the tool material is Platinum coated Carbide- ISO US735. We concluded that surface quality is improving as we increase the spindle speed, and the optimum value of surface roughness is obtained at the maximum speed of 130 and least quality of surface roughness is obtained at the low spindle speed of 90 with the increase in feed rate the surface roughness is getting decrease. Awadhesh Pal et al., [10]deals with machinability assessment through experimental investigation during hard and soft turning of Hardened Steel the work piece material used in this paper is AISI 4340 steel during hard of $55 \mathrm{HRC}$ and soft turning of 35 and $45 \mathrm{HRC}$ and the tool material is TiC mixed alumina ceramic tools. It has been observed to decrease with increase in hardness of the work piece. That interface temperature increases with increase in work piece hardness. S.R. Das et al., [11] shows with Optimization of surface roughness in hard turning of AISI 4340 Steel using coated carbide inserts. The work piece used in this paper is AISI 4340 and the tool material is multilayer coated carbide insert (TiN/TiCN/Al2O3/ZrCN) CNMG 120408 insert. Feed was found to be most significant parameter for the work piece surface roughness (Ra) with a percent contribution of $52.55 \%$. Lohar and Nanavaty [12] analysis the Performance evaluation of minimum quantity lubrication using CBN tool during hard turning of AISI 4340 with dry and wet Turning the work piece used in this paper is AISI 4340 and the tool material is CBN insert TNMA160404 Grade PB250 There is 40\% decrease in cutting forces during MQL and wet flood condition it was about 26\% more than MQL and 19\% less than dry condition It is concluded that the cutting temperature in hard turning of hardened AISI 4340 is less as compared to dry and wet turning and gives $36 \%$ decrease in cutting temperature. Sujit Raj, Rahul Davis [13] it deals with a comparative analysis of the effects of heat treatment and turning process parameters on AISI4340 Steel .The work material used in this paper is AISI 4340 and the tool material is single point carbide coated cutting tool. Heat treated specimen have got mild and at different cutting parameters finishing of surface is better than non-heat treated specimen. After all surface roughness will depend upon the combined effect of cutting parameter and the contributing factors. Zhirafar et al., [14] deals with Effect of cryogenic treatment on the mechanical properties of 4340 steel the work piece used in this paper is AISI 4340 In general, hardness and fatigue strength of the cryogenically treated specimens were a little higher whereas the toughness of the cryogenically treated specimens was lower when compared to that of the conventionally treated steel. Cryogenic treatment was a small reduction in the quantity of "retained austenite", which was transformed to marten site by applying the cryogenic treatment. Atul Prabhakar Kulkarni and Vikas G. Sargade [15] improve the Characterization and Performance of AlTiN, AlTiCrN, TiN/TiAlN PVD Coated Carbide Tools While Turning SS 304 the work piece used in this paper is SS 304 steel and the tool material is CNMA120408 CBN, PCD .The cutting parameters are cutting speed, feed, depth of cut AlTiN, AlTiCrN, and TiN, TiAlN coatings show dense columnar structure. Large nose wear due to abrasion and chipping was a dominated mode of wear in case of AlTiN coated tool. The selections of work and tool materials are based on the literature survey with industrial applications. 


\subsection{Effect of Residual Stress}

There are few researchers working on the methods of prediction and prevention of residual stresses [16]. El-axir deals with the method of modeling residual stress distribution in turning for different materials showed that the residual stress[17]. It also continued to decrease across the section becoming either tensile or compressive at large depths. In test 1 the cutting speed is $117 \mathrm{~m} / \mathrm{min}$ and feed is 0.356 , tensile strength is $360 \mathrm{mpa}$ in the test 2 the cutting speed is $171 \mathrm{~m} / \mathrm{min}$ and the feed is $0.2 \mathrm{~mm} / \mathrm{rev}$, tensile strength is $360 \mathrm{mpa}$.The researcher further investigated that the maximum residual stresses always occurs beneath the machined surface rather than on the nearest layer to the machined surface. Rech and Moisan [18] revealed in their examination of the machined surfaces using three-dimensional topography that feed rate was the main parameter that influenced the surface roughness compared to the influence of cutting speed, Finish cutting was conducted at a cutting speed $V c$ in the range of 50 to $250 \mathrm{~m} / \mathrm{min}$, a feed rate $f$ in the range 0.05 to $0.2 \mathrm{~mm} / \mathrm{rev}$ and a depth of cut of $a p=0.15 \mathrm{~mm}$. whereas cutting speed was the major parameter that influenced the residual stress level. Cutting speed tends to increase the external residual stress, irrespective of the feed rate in the range of 50 to 150m. Dahlman et al., [19] revealed that rake inclination had the strongest influence on the residual stresses. The compressive stresses became greater with increased feed rate. Different cutting depths did not generate different stress levels. Rake angle $-6^{\circ},-21^{\circ}$, $-41^{\circ},-61 \circ$, Depth of cut Constant at $0.1 \mathrm{~mm}$ Feed Constant at $0.1 \mathrm{~mm} / \mathrm{rev}$, Speed Constant at $110 \mathrm{~m} / \mathrm{min}$. The results showed that it was possible to produce tailor-made residual stress levels by controlling the tool geometry and cutting parameters. A greater negative rake angle gave higher compressive stresses as well as a deeper affected zone below the surface. The result of tests performed revealed that compressive stresses were always generated below the surface. Liu et al., [20] showed that the tool nose radius affected the residual stress distribution significantly. It was further investigated that as the tool wear increased, the residual stress at the machined surface shifted to tensile stress range and the residual compressive stress beneath the machined surface increased greatly. Cutting speed $120 \mathrm{~m} / \mathrm{min}$, Feed speed: $0.1 \mathrm{~mm} / \mathrm{rev}$, Depth of cut: $0.1,0.2 \mathrm{~mm}$. The tool nose radius affected the residual stress at the machined surface significantly at early cutting stage. The residual stresses at the machined surface shifted to tensile range with the increase of the tool nose radius. It was concluded that the effect of the nose radius on the residual stress distribution decreased greatly with the increase of the tool wear. Umbrello et al., [21] presented a predictive model based on the artificial neural network approach that can be used both for forward and inverse predictions. The three layer neural network was trained on selected data from chosen numerical experiments on hard machining of 52100 bearing steel, and the numerical results showed that more compressive residual stress in both axial and circumferential direction of the machined surface were obtained if higher values of the feed rate were chosen. Outeiro et al., [22] concluded that the residual stresses were tensile at surface and gradually shifted to compressive values beneath the surface before stabilizing at the level corresponding to that found in the work material before machining. For the range of cutting conditions investigated, residual stresses generated by turning AISI 316L were also tensile and high at the machined surface, although not as high as those obtained by turning Inconel 718 . The higher surface residual stresses were generated when machining was done with the uncoated tool than the coated tool. Moreover, higher residual stress values were obtained on the transient surface than on the machined surface. Xuepinga et al., [23] in their experiments showed that compressive residual stress dominated the hard turned surface up to a depth of $0.1 \mathrm{~mm}$ for the average residual stress along the subsurface, the cutting speed had the most significant impact, followed by depth of cut, and finally feed rate. The optimal combination of cutting speed, depth of cut, and feed rate was found to be $(0.5 \mathrm{~m}=$ $\mathrm{s}, 0.135 \mathrm{~mm}, 0.25 \mathrm{~mm}=\mathrm{rev}$ ). This work showed that it was possible to simulate complex machining process, such as metal cutting. The residual stress is the major response on 
turning operation. Reduction of residual stress is to reduce the tool wear as well as to high production. Based on the literature survey we are going to conduct the experimental turning operation.

\subsection{Effect of Tool Wear}

When the tool wear reaches a certain limit, the tool or active edge has to be replaced for the better machining performance. [24] Flank wear is the major wear of the cutting tool material.it is under the category of abrasive wear. Flank wear is formed on the nose of the cutting tool. Flank wear is directly formed on the work material. The crater wear appears on the top of the cutting tool material. [25] Sitk1 Akincioğlu et al., [26] reviewed the cryogenically treated tools that deals cryogenic treatment is an effective method that enhances the tool life and wear resistance of cutting tools. Important parameters in cryogenic treatment which affect tool performance are cutting tool type, cooling speed, soaking period, soaking temperature, and tempering process. Nitrogen constitutes a significant portion $(78.03 \%)$ of the atmosphere, and liquid nitrogen, the most commonly used gas in cryogenic treatment applications is generally abbreviated as liquid nitrogen. Cryogenic tool treatment increases the hardness, wear resistance, toughness, abrasive resistance, and tool life of cutting tools Reddy et al., [27] conducted a machining study on AISI 1040 steel by applying cryogenic treatment to P-40 tungsten carbide tools. He found that deep cryogenic treatment enhanced the electrical conductivity of the carbide tools .The increase in thermal conductivity enhanced the heat dissipation capacity of the cutting tool and helped in decreasing the tool tip temperature, resulting in more hot hardness during machining, which led to less tool wear in the deep cryogenic treated tools compared to the untreated tools. They also found that tool life was increased by $27 \%$ and the main cutting forces were decreased by $11 \%$ with deep cryogenic treatment when compared to untreated inserts. E. O. Ezugwu et al., [28] deals with The Effect of Argon Enriched Environment in High Speed Machining of Titanium Alloy. Machining Ti-6Al$4 \mathrm{~V}$ alloy with uncoated carbide tools in an argon environment gave lower tool life compared to conventional coolant supply in all the conditions investigated. Cutting forces decreased with increasing cutting speed up to a speed of $120 \mathrm{~m}$ min-1 when machining under a conventional coolant supply and up to a speed of $110 \mathrm{~m}$ min-1 when machining in an argon enriched environment. Nose wear is the dominant uncoated carbide tool failure mode when machining Ti-6Al-4Valloy in all the machining conditions investigated. Machining titanium Ti-6Al-4V alloy with uncoated carbide produced acceptable surface finish under conventional coolant application and in an argon enriched environment. Yong et al., [29] investigated the effect of cryogenic treatment on carbide tools in the orthogonal turning of ASSAB 760 medium carbon steel. The researchers found that cryogenic treatment enhanced the chipping and flank wear of the tool. He concluded in long-term machining, cryogenic treatment was reported to lose its character since the tool was exposed to high temperatures. Gopal [30] examined PVD-coated carbide inserts and uncoated carbide inserts subjected to deep cryogenic treatment $\left(-190{ }^{\circ} \mathrm{C}\right)$. The surface finish produced on machining the work piece was better with the deep cryogenically treated carbide tools when compared to the untreated carbide tools. The cutting forces for the cryogenic treated inserts were lower than the non-cryogenic treated insert. Dogra et al., [31] in machining of AISI H11 steel using CBN, TiCN, TiN-coated carbide and untreated carbide insert tools under dry conditions. The researchers reported that free surface roughness in the CBN tools was lower than in the other tools. They reported that the wear value of the carbide tools in the subsequent machining periods was close to the wear values obtained in the CBN tools. It was concluded that, at low cutting speeds and feed rates, the carbide tools were comparable to the CBN tools in terms of life. The tool life of cryogenic treated coated carbide inserts was improved by 16-23\% in different cases in comparison with the untreated coated carbide inserts 


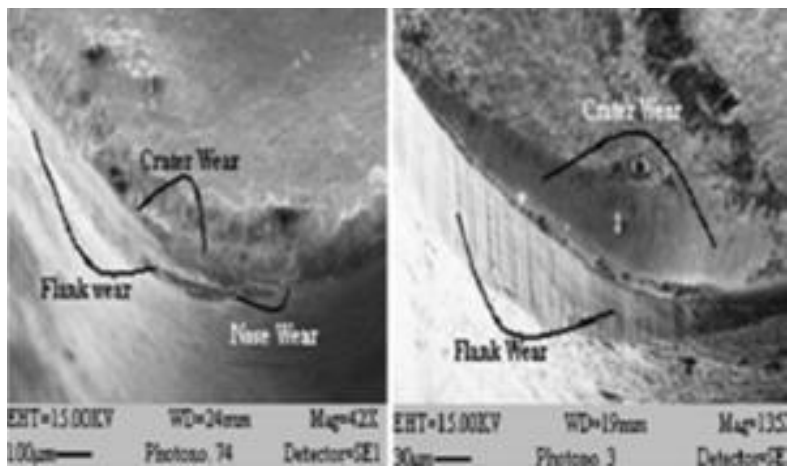

Figure 1. SEM Images of Flank and Crater Wear [31]

D. Senthilkumar et al., [32] deals with Influence of shallow and deep cryogenic treatment on the residual state of stress of 4140 steel. The shallow cryogenic treatment $\left(\mathrm{SCT}-80^{\circ} \mathrm{C}\right.$ for $5 \mathrm{~h}$ ) and deep cryogenic treatment (DCT, $-196^{\circ} \mathrm{C}$ for $24 \mathrm{~h}$ ) will creates the surface residual stress, hardness and impact toughness of 4140 steel. 4140 steel maximum compressive stresses develop after DCT, before tempering. This was highlighted to positively influence the state of stress after stress relieving. Compared to tensile stresses observed in CHT and SCT samples, residual compressive stresses were found after DCT. Shivdev Singh et al., [33] conducted the experimental analysis of cryogenic treatment on coated tungsten carbide inserts in turning. Three different tungsten carbide inserts coated with aluminum chromium nitride, titanium nitride and uncoated were taken and treated cryogenically. The inserts were subjected to tempering cycles to relieve the stresses induced by cryogenic treatment. Cryogenic treatment of TiN and AlCrN coated tungsten carbide inserts resulted better performance than uncoated when treated cryogenically. TiN coated inserts gave better performance followed by $\mathrm{AlCrN}$ coated as compared to uncoated of cryogenic treatment. Lower cutting forces have been observed in case of cryogenically treated TiN coated as compare to AlCrN coated and uncoated treated tools. Dilip Jerold and M. Pradeep Kumar [34] performed with Machining of AISI 316 Stainless Steel under Carbon-Di-Oxide Cooling. This resulted in lesser amount of wear in the rake and flank region of the cutting tool, producing the better surface finish. $\mathrm{CO} 2$ cooling will be more advantageous as far as the high cutting velocities and feed rates are concerned as it produces better chip breakability and acceptable form of chips. $\mathrm{CO} 2$ is a potential alternative for other cryogenic coolants especially in industrial conditions.

\subsection{Effect of Cutting Tool Temperature in Turning}

Al-zkeri et al., [35] investigated the effects of edge radius of a round-edge coated carbide tool on chip formation, cutting forces, and tool stresses in orthogonal cutting of an alloy steel 42CrMo4 (AISI 4142H). The external diameter of the tube was $78 \mathrm{~mm}$, with a wall thickness of $3 \mathrm{~mm}$ corresponding to the width of cut. A cutting speed of $150 \mathrm{~m} / \mathrm{min}$ and a feed rate of $0.1 \mathrm{~mm} / \mathrm{rev}$ were selected. The rake angles, cutting edge angles, relief angles and nose radius affect the life of tool by varying degrees. The cutting forces, tool temperature and tool wear decrease, with increase in rake angle. When the side cutting edge angle is increased, the tool temperature and wear of cutting tool decreased. Also increase in nose radius reduces the cutting temperature. Zhou et al., [36] studied the effect of chamfer angle on wear of PCBN cutting tool. Results indicated that tool life reaches to its maximum up to $15^{\circ}$ chamfer angle and after that it reduced drastically. The tool life was Measured up to the value of $0.2 \mathrm{~mm}$ flank wear, in order to avoid excessive white layer induced on the work-piece surface due to the higher temperature under the large flank wear. As per Finite Element analysis the cutting edge with $15^{\circ}$ chamfer angle had the smallest value of flank wear as compared to other cutting tools Kevin Chou and Hui 
Song [37] performed an experimental investigation in finish turning of hardened AISI 52100 steel. It was noticed that large tool nose radius only gave finer surface finish, but comparable tool wear with small nose radius tools. Also it was found that specific cutting energy slightly increased with increase in tool nose radius. The cutting tool life based on flank wear increased with increase in the nose radius. However, it reached a constant at nose radius greater than $0.4 \mathrm{~mm}$. On the other hand, tool life based on surface finish showed a local maximum at $0.8 \mathrm{~mm}$ nose radius. It was stated that the tool nose radius also affects uncut chip geometry, and thus, ratio of uncut chip thickness to edge radius may affect plowing forces in the hard turning process. Jacobson [38] investigated the surface integrity of hard turned M50 steel. Tests were conducted using different tools while also varying the depth of cut. It was found from the investigation that M50 consistently showed compressive residual stress at the surface. The amount of residual stress varied from -600 to $-1300 \mathrm{Mpa}$. It was noticed that the effective rake angle and nose radius of the tool affect the amount of residual stress generated. Also it was concluded that higher negative rake angle and smaller nose radius create a more compressive residual stress profile. Fang and Fang [39] employed multiple criteria including the cutting force, the thrust force, the chip thickness, and the tool-chip natural contact length to compare the experimental and theoretical predictions from both the analytical and finite element models. The analytical results showed that, when the cutting speed was increased, the tool-chip friction along the tool rake face and on the round tool edge decreased. The error of prediction from the analytical and finite element models was typically less than $12 \%$. The maximum temperature occurs on the round tool edge in small-feed-rate finish machining.Muammer Nalbant et al., [40] investigated the effects of cutting speed and cutting tool geometry on cutting forces. Inconel 718, nickel-base super alloy .Machining was carried out for four different cutting speeds such as $150 \mathrm{~m} / \mathrm{min}, 200$ $\mathrm{m} / \mathrm{min}, 250 \mathrm{~m} / \mathrm{min}$, and $300 \mathrm{~m} / \mathrm{min}$, but the depth of cut of $2 \mathrm{~mm}$ and the feed rate of 0.20 $\mathrm{mm} / \mathrm{rev}$ were kept constant. It was found from experimental result that, the lowest main cutting force, which mainly depends on tool geometry. From the literature review, it is clear that variation in tool geometry is one of the major parameters to be considered in order to enhance the Turning productivity in terms of cutting zone temperature, flank wear and surface integrity.

\subsection{Methodology in Turning}

R. Suresh et al., [41] deals with Machinability investigations on hardened AISI 4340 steel using coated carbide insert the methodology used in this paper is design of experiment and response surface methodology. The response surface methodology is a modeling tool used for establishing the relationship between the independent variables and the desired response. Thus 108 trials based on FFD were planned. As per ANOVA, the calculated value of F-ratio of proposed model should be more than F table for the model to be adequate for a given confidence interval. ANOVA and it is found that the developed models are significant at $99 \%$ confidence interval as F-ratio of all the five models is greater than 3.13 (F-table $(14,93,0.01)$ ). The goodness of fit of the proposed models was also tested through the coefficient of determination (R2), which is the proportion of variation in the dependent parameter explained by the polynomial model. These plots were generated considering two parameters at a time, while the other parameters were kept at the center level. With the further increase in depth of cut, the material removal rate increases which contribute to increase in machining force. The author suggests that the machining force can be minimized by employing Lower values of feed rate, depth of cut and machining time with higher cutting speed. Pu Z et al., [42] deals with Finite Element Simulation of Residual Stresses in Cryogenic Machining of AZ31B Mg Alloy. The methodology used in this paper is finite element simulation. The proposed numerical procedure developed in this paper employs a FE based thermomechanical model formulation of the orthogonal hard turning process. In particular, 
numerical prediction of both circumferential and axial residual stresses was found to be consistent with those experimentally Measured that sequential cuts deeply affect the residual stress distribution and they have to be considered during the FE modeling FE model takes the initial residual stress into account proposed FEM procedure could be used for intelligent process parameter selection to achieve a more desirable final surface integrity state.

\subsection{Characteristics Analysis}

Saoubi et al., [43] showed that Residual stress analysis in orthogonal machining of standard and resulfurized AISI 316L steels .In this paper the residual stress is measured by X-ray diffraction method. Wavelength Radiation Filter Bragg angle 2_ (8) Fe 16.531 _ $10 \ddot{y} 6$ ÿ1.429 _ $10 \ddot{y} 6 \mathrm{Mn} \mathrm{Ka} \mathrm{Cr} 152.3$ (hkl) = (311). Moreover, during the tests, an experimental analysis of the temperature in the cutting zone in association with cutting force measurement enabled discussion of the physical mechanisms involved in residual stress generation. Edoardo Capello[44] shows that Residual stresses in turning Part I: Influence of process parameters. Axial residual stresses were measured at two random sites for each specimen using an X-ray diffractometer. The main characteristics of this apparatus are the following: $\Omega$ geometry, $\Psi=0$, Cr tube $(27 \mathrm{kV}, 6 \mathrm{~mA})$, scintillation detector, Lorentz correction applied, vanadium filter, $0.01 \mathrm{~mm}$ average measurement depth, $1 \mathrm{~mm}$ opening collimator, $3 \mathrm{~mm} 2$ measurement area. The alignment of the measuring device was carefully tested and the zero setting controlled with iron powder. Due to the relatively large radius of the specimens, no correction was made for the curvature.

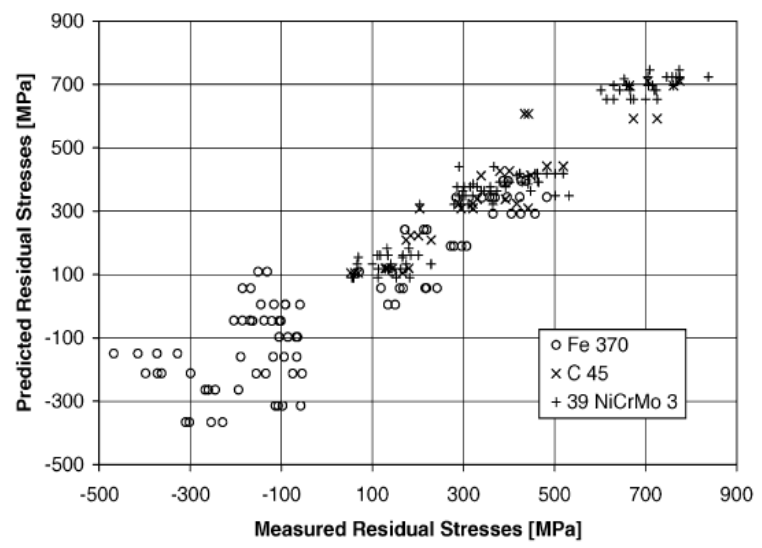

Figure 2. Measured Residual Stress with Predicted Stress [44]

Bensely et al., [45] deals with Effect of cryogenic treatment on distribution of residual stress in case carburized En 353 steel. X-ray diffraction (XRD) measurements are based on the change in the interplanar spacing (strain) by virtue of load or temperature or both. The data were acquired in several $\Psi$ angles (in range of $0-45^{\circ}$ ) and the stresses were calculated by the classical $\sin 2 \Psi$ method. The peak position was calculated by the cross correlation method. The parameters selected for experimentation Due to the limited penetration (4_m for chromium radiation in steel) of X-ray only surface stresses could be measured. Hence stresses at shallow points in the samples were determined by repeating the measurements after removing (electro polishing) layers of known thickness. When performing layer removal for residual stress depth profiling it is important to consider any redistribution or relaxation in the residual stress in the exposed surface. A generalized solution proposed by sikarskie based on the original solutions of Moore and. For electro polishing, the electrolyte used consisted of $80 \mathrm{~cm} 3$ perchloric acid (70\%), $700 \mathrm{~cm} 3$ ethanol, $100 \mathrm{~cm} 3$ butoxyethanol and $120 \mathrm{~cm} 3$-distilled water. The jet polishing was 
performed at temperatures ranging from $253 \mathrm{~K}$ to $263 \mathrm{~K}$ at a voltage between $20 \mathrm{~V}$ and $30 \mathrm{~V}$ and at a current of about 600-900 mA. The specimens were jet polished using the electrolyte at $283 \mathrm{~K}$. The peaks on the XRD patterns were indexed with the X-ray polycrystalline powder diffraction files (International Center for Diffraction Data (ICDD)).

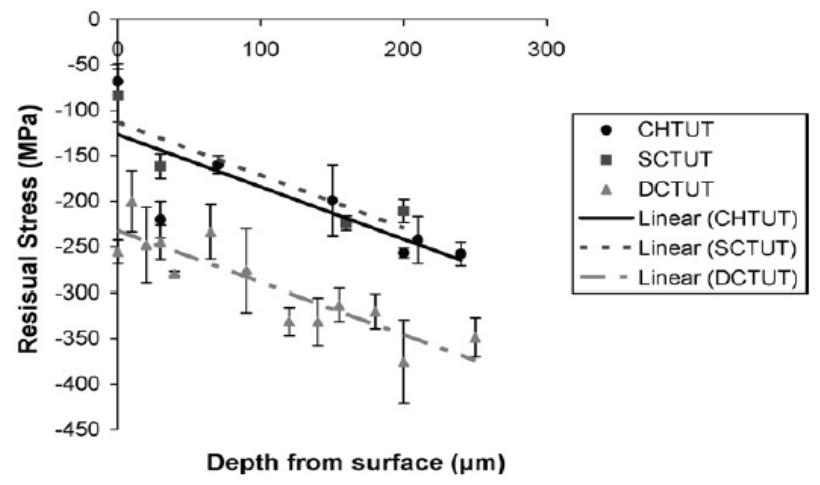

Figure 3. Residual Stress\& Depth of Surface [45]

W. Jomaa et al., [46] shows that An Investigation of Machining-Induced Residual Stresses and Microstructure of Induction-Hardened AISI 4340 Steel. The residual stresses were measured in depth using the X-ray diffraction technique and electrochemical polishing process. X-ray parameters used in the present work are: Radiation, $\mathrm{Cr} \mathrm{K} \alpha$, Bragg angle (20), $156^{\circ}$, and X-ray elastic constant, $171 \mathrm{MP}$. Therefore, the measured SRS is the average of residual stresses measured over the X-ray penetration depth, which is a combination of a white layer and the plastic deformed layer. So, the measured surface residual stresses cannot be related to only the white layer. Conversely, one does not need to involve white layers to explain residual stress trends in the present work as no specific trends are observed close to the surface.

(a) hoop stress at $\mathrm{V}=128 \mathrm{~m} / \mathrm{min}$

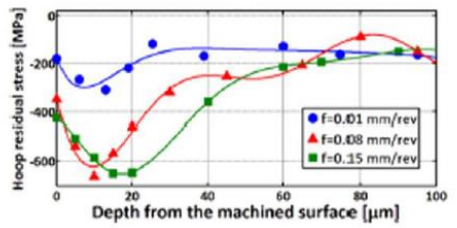

(c) hoop stress at $\mathrm{f}=0.08 \mathrm{~mm} / \mathrm{rev}$

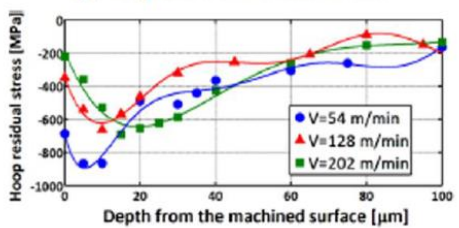

(b) axial stress at $\mathrm{V}=128 \mathrm{~m} / \mathrm{min}$

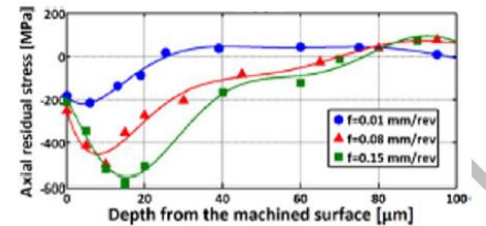

(d) axial stress at $\mathrm{f}=\mathrm{V}=128 \mathrm{~m} / \mathrm{min}$

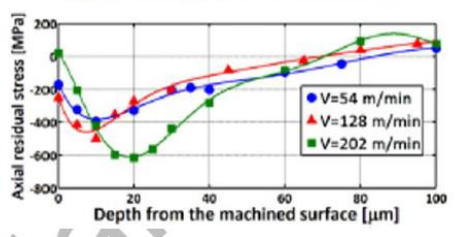

Figure 4. Residual Stress with Axial Stress [46]

\section{Conclusion}

A review of Analysis the residual stress in turning of AISI4340steel using cryogenic treatment cutting tool insert is the effective method that can be widely applied to various cutting tools. According to the tool material and machining condition cryogenic treatment applied to cutting tool insert enhances the tool wear resistance and better the residual stress due to the improves in the mechanical properties. As a result let the residual stress 
and tool wear resistance are improved due to tool geometry variation of cryogenically treated insert and cutting temperature.

It has been numerical proved that the residual stress resistance with tool wear relational is depend one another results from the experimental and analyze method to find the error value of residual stress and the tool wear.

The tool wear resulted in increasing in residual stress and machining temperature. This method can help us to reduce the production cost by increasing cutting tool performance to achieve the maximum benefit applied under optimum condition.

\section{References}

[1] G. F. Batalha, S. Delijaicov, J. B. Aguiar, E. C. Bordinassi and M. Stipkovic Filho, "Residual stresses modeling in hard turning and its correlation with the cutting forces", Journal of achievement in materials and manufacturing Engineering, vol. 24, no. 1, (2007), pp. 350-356.

[2] A. Vishwakarma, S. Jain and P. Kumar Sharma, "Analysis of effect of Minimum Quantity Lubrication on different machining parameters Cutting Force, Surface Roughness and Tool Wear by Hard Turning of AISI-4340 Alloy Steel a Review", International Journal of Advanced Engineering Research and Technology, vol. 2, no. 9, (2014), pp. 344-354.

[3] T. O" zel, Y. Karpat, L. Figueira and J. Paulo Davim, "Modelling of surface finish and tool flank wear in turning of AISI D2 steel with ceramic wiper inserts", Journal of Materials Processing Technology, vol. 189, (2007), pp. 192-198.

[4] T. V. SreeramaReddy, T. Sornakumar, M. VenkataramaReddy and R. Venkatram, "Machinability of C45 steel with deep cryogenic treated tungsten carbide cutting tool inserts", International. Journal of Refractory Metals \& Hard Materials, vol. 27, (2009), pp. 181-185.

[5] T. Tamizharasan, T. Selvaraj and-A. Noorul Haq, "Analysis of tool wear and surface finish in hard turning", International Jounal of Adv Manuf Technol, (2006), pp. 671-679.

[6] J. Verma1, P. Agrawal and L. Bajpai, "turning parameter optimization for surface roughness of ASTM a242 type-1 alloys steel by taguchi method", International Journal of Advances in Engineering \& Technology, vol. 3, no. 1, (2012), pp. 255-261.

[7] A. H. Suhail, N. Ismail, S. V. Wong and N. A. Abdul Jalil, "Optimization of Cutting Parameters Based on Surface Roughness andAssistance of Workpiece Surface Temperature in Turning Process", American J. of Engineering and Applied Sciences, vol. 3, no. 1, (2010), pp. 102-108.

[8] N. Mandal, B. Doloi and B. Mondal, "Machining Parameters Optimization of Developed Yttria Stabilized Zirconia Toughened Alumina Ceramic InsertsWhile Machining AISI 4340 Steel”, World Academy of Science, Engineering and Technology, vol. 6, no. 3, (2012), pp. 62-72.

[9] P. Srivastava and A. Arya, "Improvement in Surface Quality with Different Material as Solid Lubricant in Turning on AISI 4340 Steel", International Journal of Research, vol. 2, no. 06, (2015).

[10] A. Pala, S. K. Choudhury and S. Chinchanikar, "Machinability Assessment through Experimental Investigation during Hard and Soft Turning of Hardened Steel", Procedia Materials Science, vol. 6, (2014), pp. 80-91.

[11] S. R. Das, A. Kumar, D. Dhupal and S. K. Mohapatra, "Optimization of Surface Roughness in Hard Turning of AISI4340 Steel using Coated Carbide Inserts", International Journal of Information and Computation Technology, vol. 3, no. 9, (2013), pp. 871-880.

[12] D. V. Lohar and C. R. Nanavaty, "Performance Evaluation of Minimum Quantity Lubrication (MQL) using CBN Tool during Hard Turning of AISI 4340 and its Comparison with Dry and Wet Turning", Bonfring International Journal of Industrial Engineering and Management Science, vol. 3, no. 3, (2013), pp. 102-106.

[13] S. Raj and R. Davis, "A Comparative Analysis of the Effects of Heat treatment and turning process parameters onAISI4340 Steel", vol. 3, no. 6, (2014), pp. 129-134.

[14] S. Zhirafar, A. Rezaeian and M. Pugh, "Effect of cryogenic treatment on the mechanical properties of 4340 steel", Journal of Materials Processing Technology, vol. 186, (2007), pp. 298-303.

[15] A. Prabhakar, K. Vikas and G. Sargade, "Characterization and Performance of AlTiN, AlTiCrN, TiN/TiAINPVD Coated Carbide Tools While Turning SS 304", Materials and Manufacturing Processes, vol. 30, (2015), pp. 748-755.

[16] Y. B. Guo, W. Li and I. S. Jawahir, "Surface integrity characterization and prediction in machining of hardened and difficult-to-machine alloys: a state-of-art research review and analysis", Machining Science and Technology, vol. 13, (2009), pp. 437-470.

[17] M. H. El-Axir, "A method of modeling residual stress distribution in turning fordifferent materials", International Journal of Machine Tools \& Manufacture, vol. 42, (2002), pp. 1055-1063.

[18] J. Rech, and A. Moisan, "Surface integrity in finish hard turning of case-hardened steels", International Journal of Machine Tools \& Manufacture, vol. 43, (2003), pp. 543-550.

[19] P. Dahlman, F. Gunnberg and M. Jacobson, "The influence of rake angle, cutting feed and cutting depth on residual stresses in hard turning”, Journal of Materials Processing Technology, vol. 147, (2004), pp. 
$181-184$

[20] M. Liu, J.-I Takagi and A. Tsukuda, "Effect of tool nose radius and tool wear on residual stress distribution in hard turning of bearing steel", Journal of Materials Processing Technology, vol. 150, (2004), pp. 234-241.

[21] D. Umbrello, G. Ambrogio, L. Filice and R. Shivpuri, "An ANN approach for predicting subsurface residual stresses and the desired cutting conditions during hard turning", Journal of Materials Processing Technology, vol. 189, (2007), pp. 143-152.

[22] J. C. Outeiro, J. C. Pina, R. M'Saoubic, F. Pusavec and I. S. Zawahiri, "Analysis of residual stresses induced by dry turning of difficult-to-machine Materials", CIRP Annals - Manufacturing Technology, vol. 57, (2008), pp. 77-80.

[23] Z. Xuepinga, G. Erwei and C. Richard Liu, "Optimization of process parameter of residual stresses for hard turned surfaces", Journal of Materials Processing Technology, vol. 209, (2009), pp. 4286-4291.

[24] M. M. A. Khan and N. R. Dhar, "Performance evaluation of minimum quantity lubrication by vegetable oil in terms of cutting force, cutting zone temperature, tool wear, job dimension and surface finish in turning AISI-1060 steel”, Khan et al. / J 1790 Zhejiang Univ SCIENCE, (2006), pp. 1790-1799.

[25] G. Bartarya and S. K. Choudhury, "State of the art in hard turning", International Journal of Machine Tools \& Manufacture, vol. 53, (2012), pp. 1-14.

[26] S. Akincioğlu, H. Gökkaya and İ. Uygur, "A review of cryogenic treatment on cutting tools", International Journal of Adv Manuf Technol, (2015), pp. 1-12.

[27] T. V. Sreerama Reddy, T. Sornakumar, M. Venkatarama Reddy, R. Venkatram and A. Senthilkumar, "Turning studies of deep cryogenic treated p-40 tungsten carbide cutting tool inserts - Technical communication", Machining Science and Technology, vol. 13, (2009), pp. 269-281.

[28] E. O. Ezugwu, R. B. Da Silva, J. Bonney and Á. R. Machado, "The Effect of Argon Enriched Environment in High Speed Machining of Titanium Alloy", tribology transactions, (2005), pp. 1-15.

[29] A. Y. L. Yong, K. H. W. Seah and M. Rahman, "Performance evaluation of cryogenically treated tungsten carbide tools in turning", International Journal of Machine Tools \& Manufacture, vol. 46, (2006), pp. 2051-2056.

[30] G. Krishna, P. V. Kishore, K. Ramadevudu and G. Sikandar, Ali, "Performance evaluation of cryogenic treated tools in turning", Advances in Production Engineering \& Management, vol. 7, no. 3, (2012), pp. 187-194.

[31] M. Dogra, V. S. Sharma, A. Sachdeva, N. Mohan Suri and J. S. Dureja, "Performance evaluation of CBN, coated carbide, cryogenically treated uncoated coated carbide inserts in finish-turning of hardened steel”, International Journal of Adv Manuf Technol, vol. 57, (2011), pp. 541-553.

[32] D. Senthilkumara, I. Rajendrana, M. Pellizzari and Juha Siiriainen, "Influence of shallow and deep cryogenic treatment on the residual state of stress of 4140 steel", Journal of Materials Processing Technology, vol. 211, (2011), pp. 396-401.

[33] S. Singh, D. Singh and N. S. Kalsi, "Experimental analysis of cryogenic treatment on coated tungsten carbide inserts in turning", International Journal of Advanced Engineering Technology, vol. 3, no. 1, (2012), pp. 290-294.

[34] B. Dilip Jerold and M. Pradeep Kumar, "Machining of AISI 316 Stainless Steel under Carbon-Di-Oxide is cooling", Materials and Manufacturing Processes, vol. 27, (2012), pp. 1059-1065.

[35] J. Rech Al-Zkeri, T. Altan, H. Hamdi and F. Valiorgue, "Optimization of the cutting edge geometry of coated carbide tools in dry turning of steels using a finite element analysis", Machining Science and Technology, vol. 13, (2009), pp. 36-51.

[36] J. M. Zhou, H. Walter, M. Anders son and J. E. Stahl, "Effect of chamfer angle on wear of PCBN cutting tool", International Journal of Machine Tools \& Manufacture, vol. 4, no. 3, (2003), pp. 301-305.

[37] Y. Kelvin Chou, Chris J. Evans and M. M. Barash, "Experimental investigation on CBN turning of hardened AISI 52100 Steel", Journal of material processing Technology, vol. 124, (2002), pp. 274-283.

[38] M. Jacobson, "Surface integrity of hard-turned M50 steel", Proceedings of the Institution of Mechanical Engineers, Part B: Journal of Engineering Manufacture, (2002), pp. 47-54.

[39] N. Fang and G. Fang "Theoretical and experimental investigations of finish machining with a rounded edge tool", Journal of Materials Processing Technology, vol. 191, (2007), pp. 331-334.

[40] M. Nalbant, A. Altın and H. Go kkaya, "The effect of cutting speed and cutting tool geometry on machinability properties of nickel-base Inconel 718 super alloys", Materials and Design, vol. 28, (2007), pp. 1334-1338.

[41] R. Suresh, S. Basavarajappa, V. N. Gaitonde and G. L. Samuel, "Machinability investigations on hardened AISI 4340 steel using coated carbide insert", International Journal of Refractory Metals and Hard Materials, vol. 33, (2012), pp. 75-86.

[42] Z. Pua, D. Umbrellob, O. W. Dillon Jr. and I. S. Jawahira, "Finite Element Simulation of Residual Stresses in Cryogenic Machining of AZ31B Mg Alloy", Procedia CIRP 13, (2014), pp. 282-287.

[43] R. M'Saoubia, J. C. Outeirob, B. Changeuxa, J. L. Lebruna and A. MoraÄo Dias, "Residual stress analysis in orthogonal machining of standard and resulfurized AISI 316L steels", Journal of Materials Processing Technology, vol. 96, (1999), pp. 225-233.

[44] E. Capello, "Residual stresses in turning Part I: Influence of process parameters", Journal of Materials 
Processing Technology, vol. 160, (2005), pp. 221-228.

[45] A. Bensely, S. Venkatesh, D. Mohan Lal, G. Nagarajan, Rajadurai and K. Junik, "Effect of cryogenic treatment on distribution of residual stress in case carburized En 353 steel", Materials Science and Engineering A, 479, (2008), pp. 229-235.

[46] W. Jomaa, V. Songmene and P. Bocher, "An Investigation of Machining-Induced Residual Stresses and Microstructure of Induction-Hardened AISI 4340 Steel", Materials and Manufacturing Processes, (2015). 